\title{
Proceso histórico de conformación de la mentalidad colonial, y su incidencia en la construcción de los Estados nacionales en América Latina
}

\section{The Historical Process of Configuration of the Colonial Mentality, and Its Influence in the Construction of the National States in Latin America}

\section{Processo histórico de conformação da mentalidade colonial e sua incidência na construção dos estados nacionais na América Latina}

Bolívar Rojas-Vargas

Comunicador

Maestría en Estudios Latinoamericanos

Universidad Nacional Costa Rica

Recibido:14/11/2017 Aceptado: 30/12/2017

Lo nuestro no hay nadie que nos los quite por más nieve que tiren aquí la nieve se derrite aunque siembren las raíces como les dé la gana los palos de guanábana no dan manzanas Hijos del cañaveral, Residente

Resumen

La construcción de las identidades culturales en América Latina atraviesa distintos momentos históricos, caracterizados por choques, encuentros y diálogos entre diversas cosmovisiones. Un recorrido histórico por los hechos más relevantes del subcontinente permite identificar los momentos 
claves en la conformación de las identidades culturales latinoamericanas. Este recorrido se propone evidenciar también la conformación de la mentalidad colonial que ha determinado el rumbo de nuestros pueblos.

Palabras clave: identidades culturales latinoamericanas, Estados nacionales, América Latina, mentalidades, pensamiento latinoamericano.

\section{Abstract}

The construction of the cultural identities in Latin America goes through different historical moments, characterized by clashes, meetings and dialogs between different worldviews. A historic tour of the most important facts of the subcontinent allows identifying the key moments in the configuration of cultural identities in Latin America. This tour also intends to show the configuration of the colonial mentality that has determined the course of our peoples.

Keywords: Latin American cultural identities, national states, Latin America, mentalities, Latin American thought

\section{Resumo}

A construção de identidades culturais na América Latina passa por diferentes momentos históricos, caracterizados por choques, encontros e diálogos entre diferentes cosmovisões. Um percurso histórico pelos fatos mais relevantes do subcontinente permite identificar os principais momentos da conformação das identidades culturais latino-americanas. Este percurso também propõe colocar em evidencia a conformação da mentalidade colonial que determinou o rumo dos nossos povos.

Palavras-chave: identidades culturais latino-americanas, estados nacionais, América Latina, mentalidades, pensamento latino-americano.

\section{Origen}

Nacemos con un propósito, desde nuestra concepción estamos sujetos a expectativas y esperanzas de nuestros progenitores y sus familias. Estamos marcados por quienes nos anteceden, por sus ideas, sus deseos, sus creencias y sus aspiraciones. Las identidades personales surgen a partir de un marco de referencia establecido por nuestra realidad inmediata: la familia, el contexto social, político, económico y el espacio físico.

Las condiciones estructurales configuran también las identidades sociales y culturales, originadas a partir de la interacción entre grupos sociales en territorios comunes. La historia de América Latina se caracteriza por la confluencia de distintos factores que inciden en la construcción de identidades nacionales y en la estructuración de los Estados latinoamericanos.

14 Proceso histórico de conformación de la mentalidad colonial, y su incidencia en la construcción de los Estados nacionales en América Latina Bolivar Rojas-Vargas

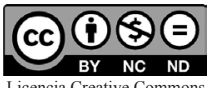

icencia Creative Commons Atribución-No-Comercial
SinDerivadas 3.0 Costa Rica

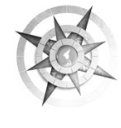


El peso del dominio colonial marca a los pueblos de América Latina. Los Estados nacionales, surgidos a partir de los límites de la administración colonial, responden a los intereses, las expectativas y las aspiraciones de grupos sociales específicos, los cuales se articulan de diferentes maneras para cumplir sus objetivos.

La arquitectura de las principales capitales latinoamericanas da cuenta de la influencia de los grupos detentores del poder estatal y el eclecticismo de sus gustos. Las mezclas de estilos arquitectónicos evidencian sus valoraciones estéticas, sus modelos de ciudad, a los que querían parecerse. Las fachadas de concreto imitan el estilo de teatros y catedrales europeas, las oligarquías locales anhelaban que sus ciudades se codearan con París y Londres.

La aspiración por copiar los modelos europeos y el estadounidense (a partir de inicios del siglo XX) trasciende la arquitectura. Las instituciones del Estado, las leyes, la educación y la cultura son impuestas bajo criterios originados en las antiguas metrópolis coloniales.

La construcción de las identidades culturales en América Latina atraviesa distintos momentos históricos, caracterizados por choques, encuentros y diálogos entre diversas cosmovisiones. Los criollos, claves en las luchas de independencia, mantuvieron su sitio de privilegio en las nacientes naciones y se mimetizaron con otros grupos de poder integrantes de las élites nacionales.

Un recorrido histórico por los hechos más relevantes del subcontinente permite identificar los momentos claves en la conformación de las identidades culturales latinoamericanas. Este recorrido evidenciará también la conformación de la mentalidad colonial que ha determinado el rumbo de nuestros pueblos.

\section{Concepción}

Con la llegada de los colonizadores europeos la población originaria del Nuevo Mundo sufrió un descenso significativo, a los asesinatos cometidos por los conquistadores se sumaron las muertes producidas por las enfermedades importadas desde Europa.

El arribo de los colonizadores europeos, violento y aniquilador, representó sin embargo la gestación de identidades nacionales que se construyen desde hace más de quinientos años.

El criollo Simón Bolívar recordaba a los legisladores del recién instaurado Congreso de La Angostura en 1819 que "nuestro pueblo no es el europeo, ni el americano del norte, que
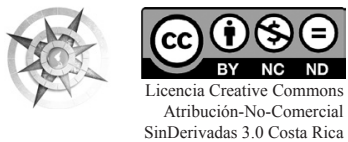

Proceso histórico de conformación de la mentalidad colonial, y su incidencia en la construcción de los Estados nacionales en América Latina 
más bien es un compuesto de África y de América, que una emanación de la Europa; pues que hasta la España misma, deja de ser Europa por sangre africana, por sus instituciones, y por su carácter" (citado por Baeza, 1976, $\mathrm{s} / \mathrm{p}$ ). El Libertador venezolano advertía a los responsables de construir la institucionalidad y el entramado legal de la Gran Colombia de la diffcultad del proyecto que emprendían, encarnada en la diversidad de orígenes étnicos de la población.

Es imposible asignar con propiedad, a qué familia humana pertenecemos. La mayor parte del indígena se ha aniquilado, el europeo se ha mezclado con el americano y con el africano, y éste se ha mezclado con el indio y con el europeo. Nacidos todos del seno de una misma madre, nuestros padres diferentes en origen y en sangre, son extranjeros, y todos difieren visiblemente en la epidermis; esta desemejanza trae un reato de la mayor trascendencia (Baeza, 1976).

La nueva "familia humana" engendrada con la violenta conquista se enriqueció genética y culturalmente con el despiadado tráfico de esclavos africanos. Poblaciones enteras fueron secuestradas y trasladadas a América durante tantos años de comercio de esclavos (Moreno, 2000). Moreno Franginals (2000) afirma que más de
9 millones de africanos fueron desplazados en el mayor traslado coercitivo de personas en la historia. Pese a los procesos de deculturación a los que fueron sometidos, como la separación de etnias y el trabajo alienante, elementos culturales africanos se incorporaron a las nuevas naciones: resultado de una cruenta lucha de clases y un proceso constante de transculturación-deculturación. El autor cubano Miguel Barnet retrata en Biografía de un cimarrón (1966) la vida de Esteban Montejo, esclavo nacido en Cuba que vivió el proceso de abolición de la esclavitud y las luchas de independencia de la isla. El texto novelado da cuenta de las tradiciones africanas aún vigentes a mediados del siglo XX, pese a la discriminación y rechazo hacia la población negra (Barnet, 1966).

El régimen colonial español y portugués en América Latina estableció los límites de las identidades culturales nacientes. La situación de marginación a la que es sometida la población indígena se institucionalizó en el Estado colonial mediante la encomienda y el repartimiento. Los españoles cumplen con su sagrado deber de civilizar y cristianizar al indio, y mientras se ganan el cielo disfrutan de la mayor riqueza del Nuevo Mundo: la fuerza de trabajo (Cuevas y Mora, 2015). La legitimidad otorgada

16 Proceso histórico de conformación de la mentalidad colonial, y su incidencia en la construcción de los Estados nacionales en América Latina Bolivar Rojas-Vargas
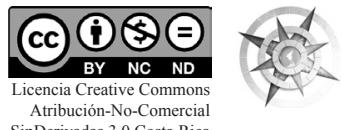
por la Iglesia católica permitió a las metrópolis explotar yacimientos de plata ubicados en México y Perú. Los colonizadores europeos insertaron a los territorios colonizados de forma dependiente en un incipiente mercado mundial (ídem).

La colonia fue el periodo de gestación de las futuras identidades culturales americanas. Los procesos de emancipación del poder colonial representaron el nacimiento de nuevos proyectos de Estados o administraciones políticas autónomas en el continente americano. Las batallas de independencia fueron el parto que dio vida a las futuras naciones latinoamericanas.

\section{Alumbramiento}

Los criollos tuvieron un papel central en las luchas de independencia y continuaron ejerciendo un rol protagonista en los primeros años de los incipientes Estados. Simón Bolívar expresó su anhelo de superar los límites administrativos coloniales y construir una Patria Grande, que uniera a los territorios recién emancipados del dominio español. La consciencia de las dificultades representadas por la diversidad étnica y cultural refleja la sensibilidad de Bolívar.
El concepto antiguo de nación, reseñado por Torres Rivas como equivalente a comunidad étnica, con elementos culturales y lingüísticos que se refuerzan mutuamente, estaba muy lejos de conformarse en el Nuevo Mundo (Torres, 2009). A la diversidad étnica se sumaba un abanico de expresiones culturales y el limitado alcance del castellano como lengua franca entre las poblaciones de las provincias liberadas.

"Roma y la Gran Bretaña son las naciones que más han sobresalido entre las antiguas y modernas; ambas nacieron para mandar y ser libres", expresó Bolívar a los legisladores de La Angostura (Baeza, 1976). Inglaterra es para el Libertador un modelo ejemplar de nación; un ejemplo a imitar para construir la Patria Grande. Al igual que Bolívar, la mayor parte de las élites latinoamericanas vieron en Europa el faro de la civilización, el camino a seguir de los nuevos Estados.

La colonia estableció en el Nuevo Continente una estructura económica "hacia afuera", de exportación de materias primas conducidas hasta la metrópoli europea (Cuevas y Mora, 2015). La independencia no varió sustancialmente la economía de los nuevos Estados, incorporados al capitalismo mercantilista como

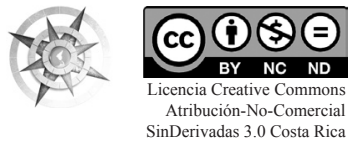

Proceso histórico de conformación de la mentalidad colonial, y su incidencia en la construcción de los Estados nacionales en América Latina 
proveedores de productos agrícolas y minerales, dependientes de los mercados europeos.

Los nuevos Estados rompieron sus lazos comerciales con el imperio español. Como recién nacidos separados del cordón umbilical, buscaron con avidez nuevas formas de nutrirse: un pezón rebosante que saciara su hambre de bienes manufacturados, su sed de bellas artes y ciencia. Francia e Inglaterra satisficieron las necesidades y aspiraciones de las élites criollas, apropiadas del poder estatal.

Es interesante reflexionar sobre las simpatías de los ingleses con las ideas y las luchas de Simón Bolívar. Inglaterra pudo acceder sin restricciones al mercado del Nuevo Mundo a partir del triunfo de las sublevaciones americanas. La situación de rezago de la Corona Española frente a los ingleses tras la Revolución Industrial se extrapoló al Nuevo Continente. Inglaterra y otras naciones europeas se enriquecieron con las materias primas extraídas desde las islas del Caribe hasta Tierra del Fuego. París y Londres se convirtieron en los nuevos centros resplandecientes (Cuevas y Mora, 2015). Para los grupos dominantes criollos, responsables de importar bienes manufacturados y artículos de lujo, lo europeo y norteamericano era motivo de admiración y representaba a la civilización.

La sociedad de los nacientes Estados no sufrió mayores cambios con los procesos de independencia. Las poblaciones indígenas, negras y mestizas mantuvieron su relación de subordinación con los criollos, recién instaurados a la cabeza de las administraciones políticas locales. La identidad criolla construida en Guatemala a partir de la segunda mitad del siglo XIX es una muestra clara de la marginación a la que se sometió a grandes sectores de población. La historia oficial recuperaba el glorioso pasado indígena, el patrimonio histórico, y a la vez se denunciaba a la población indígena contemporánea como "entorpecedora del progreso y la civilización" (Taracena, 2002).

La abundancia de conflictos internos y los choques entre distintas élites locales llevaron a proyectos nacionales integradores, como la Gran Colombia, al fracaso. La República Federal Centroamericana cayó también por las luchas intestinas. El proyecto nacional, ideado por la élite criolla de ciudad de Guatemala, pretendía que las estructuras de poder del Estado independiente no cambiaran de manos, de modo que las familias criollas guatemaltecas mantuvieran el dominio

18 Proceso histórico de conformación de la mentalidad colonial, y su incidencia en la construcción de los Estados nacionales en América Latina Bolivar Rojas-Vargas
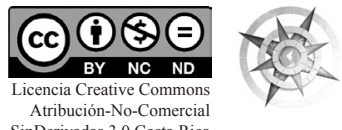
político sobre las élites provinciales (Taracena, 2002).

Los intereses políticos y económicos de los grupos de poder locales pesaron más que las ideas orientadas a construir ambiciosos proyectos nacionales. Los evidentes vínculos de las élites locales con diferentes países europeos dejan abierta la interrogante sobre el protagonismo de Londres, París y demás capitales de Europa en la caída de los planes integradores de visionarios como Bolívar. El propósito de este texto no es profundizar sobre las razones del fracaso de los proyectos de nación regionales, sino evidenciar cómo los grupos que asumen el control de los Estados privilegiaron sus deseos e intereses por sobre la unión en estructuras políticas mayores, capaces de competir con naciones europeas.

\section{Primeros pasos}

Tras el andar a gatas de los Estados surgidos a partir de la independencia de España, las constantes guerras y conflictos internos se originan en muchos países por el enfrentamiento entre conservadores y liberales. Con la prevalencia de las ideas liberales, se da un impulso a nuevos proyectos nacionales, que pueden señalarse como los primeros pasos de las naciones latinoamericanas.
En Centroamérica y en el resto de América Latina surge a mediados del siglo XIX un proceso consciente de construcción de identidades nacionales, en manos de las oligarquías liberales. La producción y comercialización de café fue un elemento clave que reforzó el papel de liderazgo ejercido por las élites e introdujo a los países centroamericanos en la economía mundial capitalista, manteniendo la relación de dependencia de bienes manufacturados importados desde la Europa industrial (Cuevas, 2016).

Los primeros pasos se dan de la mano de Inglaterra, el imperio ingles domina los mares del mundo y las primeras exportaciones de café costarricense que cruzan el Atlántico viajan hasta Londres (Instituto del Café de Costa Rica, pág. s/f).

En la invención de elementos nacionales aglutinadores por parte de las oligarquías liberales siguió valorándose como superior a la cultura y conocimientos europeos. La mentalidad colonial se integró con éxito en los proyectos de nación, pues las élites gobernantes se sentían en parte vinculadas por la sangre con Europa.

Con la llegada del siglo XX y el posicionamiento de Estados Unidos como potencia dominante en el
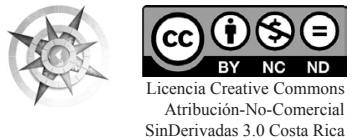

Proceso histórico de conformación de la mentalidad colonial, y su incidencia en la construcción de los Estados nacionales en América Latina 
hemisferio, las élites latinoamericanas volvieron su vista hacia el norte. "Seamos como los Estados Unidos", afirmó el argentino Domingo Faustino Sarmiento, impulsor de una política de inmigración europea y la expulsión y asesinato de los indígenas sobrevivientes a la conquista y colonización española (Cuevas y Mora, 2015).

La aspiración de orden, progreso y modernidad, equivalentes a la civilidad europea, llevó a las oligarquías liberales a rechazar importantes sectores residentes dentro de los límites estatales, y marginarlos de los proyectos nacionales. Guatemala ilustra perfectamente esta situación, el control del Estado se mantiene en manos de no indígenas desde la independencia, y la identidad nacional se ha construido alrededor de ladinos y blancos, dejando de lado a la mayor parte de la población ( $\mathrm{Ta}$ racena, 2002).

La sumisión a los intereses extranjeros por parte de los grupos de poder locales, generalmente invisibilizada por la mentalidad colonial predominante entre las sociedades latinoamericanas, generó malestar en algunos sectores de la población. Este disgusto tuvo voz en figuras que protestaron contra la constante injerencia y control que a partir de inicios del siglo XX tuvo Estados Unidos en los países de la región.

\section{Un nuevo tutor, inconformidades}

Es entonces cuando el presupuesto calculado de America for the americans sufre alteraciones impuestas por la nueva etapa en la que entran los Estados Unidos, en su expansión imperial, han librado su guerra contra España por el dominio de Cuba y Teodoro Roosevelt toma violentamente el territorio de Panamá, segregándolo de Colombia, para asegurarse la construcción, al fin, de un canal interoceánico. Y la doctrina Monroe es ahora la del big stick, bajo la cual se ocupa militarmente Haití, Santo Domingo, Cuba, Honduras, México, Nicaragua (Ramírez, 1978, pág. xiv).

Los detentores del poder consienten sin mayores protestas el papel de Estados Unidos en la región y acomodan sus intereses propios a los de la nueva potencia. Grupos de intelectuales influenciados por los planteamientos del peruano Víctor Raúl Haya de la Torre asumen posiciones críticas con respecto a la colonialidad cultural dominante en los Estados nacionales. En Costa Rica destacaron personajes como Joaquín García Monge y Carmen Lyra, quienes se solidarizan con Augusto César Sandino que lucha militarmente en

20 Proceso histórico de conformación de la mentalidad colonial, y su incidencia en la construcción de los Estados nacionales en América Latina Bolivar Rojas-Vargas

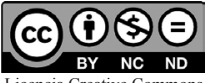

Licencia Creative Commons Atribución-No-Comercial
SinDerivadas 3.0 Costa Rica

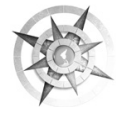


Nicaragua en contra de la ocupación estadounidense (Cuevas R., pág. s/f).

"Los dirigentes políticos, conservadores y liberales, son una bola de canallas, cobardes y traidores, incapaces de poder dirigir a un pueblo patriota y valeroso. Hemos abandonado a esos directores y entre nosotros mismos, obreros y campesinos, hemos improvisado a nuestros jefes", afirmaba Sandino justificando su lucha (Ramírez, 1978, pág. 11). Las primeras expresiones del antiimperialismo surgen de sectores ajenos al aún incipiente proceso de construcción de Estados nacionales. El cuestionamiento a la mentalidad colonial es acompañado por sectores intelectuales, con influencia limitada entre los grupos detentores del poder, cercanos en la mayoría de países a Estados Unidos.

\section{Trabajando}

Duerme, duerme negrito Que tu mama está en el campo negrito Canción de cuna popular, recopilada por Atahualpa Yupanqui

A lo largo del siglo XX y a inicios del siglo XXI, se ensayaron distintos proyectos políticos que cuestionaron en algún grado la influencia de la mentalidad colonial en los Estados latinoamericanos. La Revolución cubana de 1959 debe mencionarse como un hito de resistencia frente a la poderosa influencia de Estados Unidos en América Latina. Proyectos de diálogo político como la Comunidad de Estados de Latinoamérica y el Caribe (CELAC) rescatan las ideas de integración promovidas por Bolívar, retomadas por José Martí y que tienen eco en las motivaciones y esperanzas de Sandino. El foro en el que están representadas las naciones del continente, con excepción de Canadá y Estados Unidos, representa un esfuerzo por articular políticas regionales, sin incidencia directa de intereses ajenos a la región.

Es importante destacar que la mayor parte de los Estados latinoamericanos reproducen hoy dinámicas políticas que responden a la mentalidad colonial. Por ejemplo en Costa Rica, el presidente Luis Guillermo Solís, electo bajo una plataforma de rechazo a las políticas neoliberales de la década de 1990, renunció a cuestionar significativamente el modelo de desarrollo seguido por el país desde la implementación del Consenso de Washington. Además en la cuarta reunión cumbre de la CELAC, en la que Solís fue anfitrión, se generó un conflicto con el presidente Ortega de Nicaragua, que pretendía dar voz a representantes de la lucha independentista

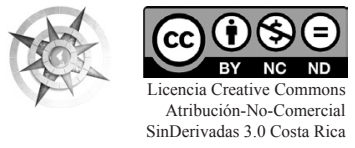

Proceso histórico de conformación de la mentalidad colonial, y su incidencia en la construcción de los Estados nacionales en América Latina 
de Puerto Rico. Solís no lo permitió (Cambronero, 2015).

"Come to Costa Rica, Emma. Perhaps in a few weeks it will be a good place to celebrate", afirmaba el presidente Solís en un impecable inglés, a la vez que tocaba en el piano los acordes de "City of Stars", del musical estadounidense La la land. El esfuerzo publicitario de Solís para promocionar los atractivos turísticos de Costa Rica se lanzó en el fin de semana de la entrega de los premios de la Academia de Cine de Hollywood, los célebres Premios Oscar, en los que la actriz Emma Stone resultó reconocida como mejor actriz (Arias, 2017). No hay indicios de que Stone haya aceptado la invitación del presidente centroamericano, sin embargo, la participación de Solís fue celebrada por medios de comunicación nacionales e internacionales.

El papel de las industrias culturales es fundamental en la construcción de identidades nacionales, y el protagonismo de Estados Unidos configura la colonialidad cultural en la que vivimos. Este tema trasciende el propósito de análisis del texto, pero es necesario plantearlo para considerar un abordaje más integral sobre los alcances materiales de la mentalidad colonial en la construcción de Estados nacionales.
El atrevimiento de tomar decisiones en interés de las grandes mayorías de los pueblos latinoamericanos se pagó con sangre durante el siglo XX. Los pasos más audaces dados por los inmaduros Estados de América Latina fueron castigados por las élites políticas y militares, aliadas a Estados Unidos.

Tras doscientos años de la independencia de España, los Estados de América Latina viven su adolescencia, aún sin resolver sus crisis identitarias y sin satisfacer las necesidades de sus habitantes. El peso de la mentalidad colonial augura un lento proceso de transformación, que depende del trabajo de muchos sectores sociales.

El estudio de la identidad cultural debería acompañarse de un cuestionamiento sobre la propia identidad, reflexión sobre nuestras motivaciones, nuestros gustos y preferencias y, principalmente, sobre nuestras acciones.

\section{Referencias bibliográficas}

Arias, L. (28 de febrero de 2017). VIDEO: President Solís invites Oscar nominee Emma Stone to celebrate in Costa Rica. The Tico Times.

Baeza, A. (1976). Simón Bolivar. San José: Departamento de Publicaciones, Ministerio de Cultura, Juventud y Deportes.

\footnotetext{
22 Proceso histórico de conformación de la mentalidad colonial, y su incidencia en la construcción de los Estados nacionales en América Latina Bolivar Rojas-Vargas
}
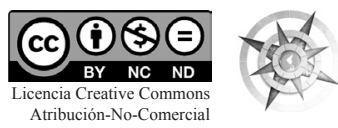
Barnet, M. (1966). Biografía de un cimarrón (2016 ed.). La Habana: Editorial Letras Cubanas.

Cambronero, N. (28 de enero de 2015). Solís y Ortega discuten por insertar tema de Puerto Rico en cumbre de la Celac. La Nación.

Cuevas, R. (s.f.). Sandino y la intelectualidad costarricense. Nacionalismo y antiimperialismo en Nicaragua y Costa Rica (1927 y 1934). Repositorio UNA. Recuperado en el 2017, de http:// www.repositorio.una.ac.cr/bitstream/ handle/11056/2894/recurso_982. pdf? sequence $=1 \&$ is Allowed $=y$

Cuevas, R. Mora, A. (2015). Buscando el futuro: crisis civilizatoria y posneoliberalismo en América Latina. San José: EUNED.

Cuevas, R. (2016). Identidad y Cultura en Centroamérica. San José: Editorial UCR.
Instituto del Café de Costa Rica. (s.f.). icafe.cr. Recuperado el 22 de abril de 2017, de http://www.icafe.cr/ nuestro-cafe/historia/

Moreno, M. (2000). África en América Latina (2 ed.). México: UNESCO-Siglo XXI.

Ramírez, S. (1978). Sandino. San José: Departamento de Publicaciones, Ministerio de Cultura, Juventud y Deportes.

Taracena, A. (2002). El caso de Guatemala, 1808-1944. En Etnicidad, Estado y nación en Guatemala, 1808-1944 (págs. 41-133). Antigua: CIRMA.

Torres, E. (2009). La nación, problemas teóricos e históricos. En E. Torres, Centroamérica: entre revoluciones y democracia (págs. 71-125). México: CLACSO-Siglo XXI. 